\title{
Patio de Letras en su cuarta edición ${ }^{1}$
}

\author{
Carlos García-Bedoya M. \\ Departamento Académico de Literatura
}

II oy presentamos al público la cuarta edición de Patio de Letras, de Alberto Escobar ${ }^{2}$. Resulta absolutamente inusual en el Perú que un libro de crítica literaria, que un volumen que reúne trabajos de análisis textual bastante especializados, vea la luz en una cuarta oportunidad. La única explicación que cabe es que Patio de Letras ha alcanzado el estatuto de clásico, es uno de esos libros que duran, que logran superar la prueba del tiempo y mantenerse vigentes como modelos, a pesar del paso de los años. En este caso, han transcurrido treintaicinco años desde la primera edición del libro, y algunos años más desde la redacción de los estudios más antiguos que allí se incluyen, pero la obra mantiene su frescura, su poder incitante y su carácter orientador.

\section{Biblioteca de Letras}

Parece natural que un libro como éste haya sido reeditado por el Fondo Editorial de nuestra Universidad, pues se trata de un libro íntimamente ligado a San Marcos, desde su propio título, alusivo a los locales de la vieja casona

1 El presente texto fue leído el 19 de mayo del 2000, al presentarse la cuarta edición de Patio de Letras. Pocos días después ocurrió el lamentable fallecimiento de Alberto Escobar. Sea este texto un modesto homenaje a su memoria.

2 Lima: Fondo Editorial de la Universidad Nacional Mayor de San Marcos, 2000. 1a. ed., Lima: Caballo de Troya, 1965. 2a. ed., Caracas: Monte Avila, 1972. 3a. ed., Lima: Luis Alfredo Ediciones, 1995. 
del Parque Universitario, pero sobre todo porque esta obra surgió de la actividad docente de Escobar, en particular de sus memorables cursos de interpretación de textos literarios, campo en el que fue pionero en el Perú ${ }^{3}, y$ también porque ella sigue reinsertándose en la dinámica académica, estimulando la reflexión de nuevas promociones de estudiantes.

Alberto Escobar es una figura intelectual de enorme relieve. Acierta plenamente Carlos Eduardo Zavaleta al situarlo como figura mayor de la crítica literaria peruana posterior a la segunda guerra mundial, al lado de Estuardo Núñez y Antonio Cornejo Polar ${ }^{4}$. Creo que se trata de figuras emblemáticas, exponentes de sucesivas generaciones, que han contribuido a la renovación de los estudios literarios en el Perú, y que evidencian el decisivo aporte de San Marcos al desarrollo de nuestra disciplina. Pero la dimensión intelectual de Alberto Escobar crece aún más si recordamos que también ha hecho aportes fundamentales al desarrollo de la lingüística y que en el campo de la creación literaria cuenta con una producción poética no desdeñable.

Pero manteniéndome en mi campo, el campo de los estudios literarios y la crítica literaria, apuntaré que el aporte de Escobar no sólo es de dimensión nacional, sino de alcance latinoamericano. Escobar se inscribe en ese notable grupo de investigadores que, sobre todo desde los años 50, en distintas partes de Nuestra América, impulsaron la renovación de los supuestos teóricos y metodológicos con los que se trabaja en nuestra disciplina. En el caso más concreto del Perú, con la obra de Ailberto Escobar-y precisamente con los trabajos más antiguos Teeogidos cen Patio de Letras" comienza una nueva etapa en los estudios literarios peruanos ${ }^{5}$. La figura de Escobar es una de las más gravitantes en el devenir de la crítica peruana, no sólo por la amplitud, diversidad y persistencia de sus esfuerzos, sino tal vez centralmente por su afán de inscribir el hecho literario en un marco cultural, concretamente, el de una cultura desgarrada por violentas contradicciones. Crítico comprometido con la realidad peruana, Escobar se esfuerza por responder a sus dificultades y sus retos. Con una sólida formación lingüística, y plenamente empapado de

3 En 1960, Escobar inauguró en San Marcos la cátedra de Interpretación de Textos Literarios.

4 "Acercamientos a Alberto Escobar", en Patio de Letras (cuarta edición), p. XXVIII.

5 Véase el artículo que escribí en colaboración con Jesús Díaz, Camilo Fernández y Miguel Angel Huamán, "El Perú crítico: utopía y realidad", Revista de Crítica Literaria Latinoamericana 31-32 (1990): 171-218. 
los aportes de la estilística y la fenomenología, en buena medida gracias a sus años de estudio en Alemania, Escobar nutre sus propuestas ante todo en maestros de la tradición germánica, como Spitzer y Auerbach, Ingarden y Kayser. Abocado a la tarea de la interpretación de textos literarios, desde un rigor que le permite superar las limitaciones de la historia literaria positivista, del biografismo y del impresionismo, hasta entonces prevalecientes, su empeño por relacionar texto y cultura lo aleja de los peligros de un inmanentismo estrecho. En sus trabajos hermenéuticos, busca aprehender las categorías que dan cuenta de la obra como totalidad y que permiten desentrañar su estructura. En La partida inconclusa, libro que ha conocido dos ediciones y que también merecería reeditarse, sustenta su enfoque sobre las tareas de la hermenéutica literaria, sus bases teóricas y rumbos metodológicos, estableciendo relaciones entre la totalidad textual y los universos de la vida cultural y social.

Otra de sus vertientes de trabajo es la vinculada con el proceso de la literatura peruana. Pero no le interesa una historia de datos y anécdotas: en los prólogos a sus fundamentales antologías de la narración y la poesía peruanas ${ }^{6}$, se interesa por la trayectoria de estos gếneros en nuestro país, y por el modo en que se constituye una tradición propia.

Personalmente, nunca tuve la fortuna de ser alumno de Alberto Escobar, si no es a través de sus libros. Sólo pude escucharlo un par de veces, cuando ya se encontraba seriamente enfermo. Sin embargo, me siento estrechamente ligado a su magisterio. En San Marcos, por lo imenos en nuestro Departamento de Literatura, hemos 'sabido mafitener viva unátradición intelectual con un perfil muy definido. Por ello, a través de la enseñanza de mis propios maestros, siento que ha llegado a mi la voz docente de Alberto Escobar, me siento partícipe de una tradición en la cual él desempeñó un papel tan relevante, y a mi vez intento transmitir parte de su mensaje a mis propios alumnos, esperando ayudar a mantener la vigencia de esa valiosa tradición, lo que por cierto supone simultáneamente una constante renovación, para intentar estar a la altura de las cotas de excelencia académica que Escobar contribuyó a fijar.

- La narración en el Perú, Lima: Editorial Letras Peruanas, 1956; 2a. ed., Lima: Librería Editorial Juan Mejía Baca, 1960. Antología de la poesía peruana, Lima: Ediciones Nuevo Mundo, 1965: 2a. ed., (muy modificada), Lima: Peisa, 1974, 2 tomos. 
Patio de Letras, el libro que hoy presentamos, contiene sus trabajos sin duda más influyentes. En ellos concretiza Escobar sus planteamientos sobre la interpretación de textos literarios, a través de estudios acuciosos sobre obras fundamentales de nuestra tradición literaria. Como bien apunta Miguel Angel Rodríguez $\mathrm{Rea}^{7}$, se trata de una obra abierta, en el sentido de que ha venido ampliándose a través de las sucesivas ediciones con la adición de nuevos textos. En el volumen que hoy comentamos, me atrevería a distinguir tres partes claramente diferenciadas. La primera, sin duda la fundamental, está a mi entender constituida por el núcleo central de los estudios incluidos en la edición primigenia. Son por cierto los trabajos más ambiciosos y abarcadores; en ellos examina Escobar obras fundamentales de la literatura peruana. Tenemos así estudios decisivos sobre el Inca Garcilaso y sus Comentarios reales, sobre "Acuérdate de mí" de Salaverry, sobre las Tradiciones peruanas de Palma o sobre La serpiente de oro $^{8}$ de Ciro Alegría. En ellos, Escobar cala hondamente en los textos, iluminando espléndidamente sus sentidos, aprovechando creativamente el instrumental de la estilística y la fenomenología.

Una segunda parte del libro estaría constituida por estudios relacionados con dos autores que mucho inquietaron a Escobar: César Vallejo y José María Arguedas. A la obra de estos autores consagró Escobar sendos libros, ambos hitos críticos en la respectiva bibliografía vallejiana y arguediana: Cómo leer a Vallejo y Arguedas o la utopia de la lengua ${ }^{10}$. Los trabajos incorporados en Patio de Letras pueden verse como complementarios a esos libros esenciales: son a veces versiones previas oreelaboraciones de algunas partes, o añadidos y ampliaciơnes! "ge Puccinelli Converso"

El tercer segmento del libro estaría formado por los trabajos más breves, pero no por ello menos sustanciosos. Se trata de notas más concisas, dedicadas en su gran mayoría a evaluar el aporte de los escritores de su propia generación, la generación del 50, abordando un proceso literario vivo del que

7 "Patio de Letras, obra abierta", en La Casa de Cartón, segunda época. 15 (1998): 22-26.

8 Ese trabajo fue parte de su tesis doctoral de 1959. La versión completa de la tesis se publicó en 1993: La serpiente de oro o el río de la vida, Lima: Universidad Nacional Mayor de San Marcos - Editorial Lumen.

9 Lima: P.L. Villanueva Editor, 1973.

10 Lima: Instituto de Estudios Peruanos, 1984. 
él mismo se sentía partícipe. Examina así a narradores como Julio Ramón Ribeyro o Carlos Eduardo Zavaleta, y a poetas como Carlos Germán Belli, Juan Gonzalo Rose o Wáshington Delgado, y por cierto a la entrañable figura de Sebastián Salazar Bondy, entre muchos nombres más.

Escobar recorre pues en esta obra fundamental todo el espectro de la crítica literaria, desde la monografía académica y sistemática, hasta la nota breve y enjundiosa. Ojalá la presente reedición sirva para enraizar en los más jóvenes el rigor intelectual que Escobar predicó con el ejemplo.

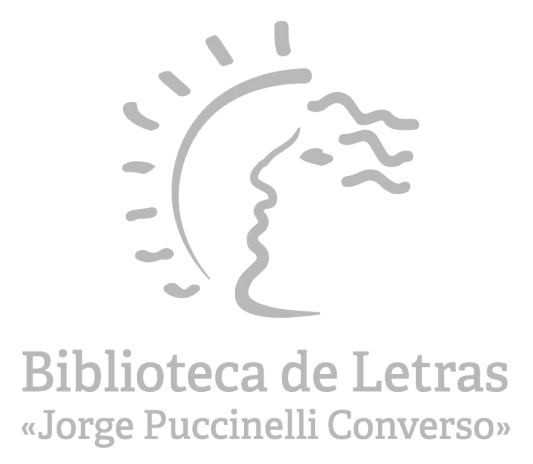

